\title{
An improved method for the synthesis of 2-, 3- and 4-dialkylaminomethylanilines
}

\author{
Béla Pete and Csaba Szántay* \\ Department of Natural Organic Compounds, Institute of Biomolecular Chemistry, Chemical \\ Research Center of the Hungarian Academy of Sciences, H-1525 Budapest, POB 17, Hungary \\ E-mail:szantay@mail.bme.hu
}

Dedicated to Professor H. C. Van der Plas on the occasion of his 80th Birthday

\begin{abstract}
Reductive amination of the formyl-, and simultaneous reduction of the nitro group of 2-, 3- and 4-nitrobenzaldehydes were accomplished to yield 2-, 3- and 4-dialkylaminomethylanilines in a single step instead of the usual alkylation followed by reduction.
\end{abstract}

Keywords: Reductive amination, reductive alkylation, aminomethylation, formal Mannich base

\section{Introduction}

Amines are ubiquitous functionalities in current drugs and pharmaceutical intermediates. The properties associated with the nitrogen atom itself, however, often make the synthesis of nitrogen-containing molecules a more painstaking endeavor than that of polyketide- or terpenederived structures. Although there are many excellent methodologies of nitrogen incorporation being already in use, among which we mention here the ANRORC transformations developed by H.C. VanderPlas and his co-workers, ${ }^{1}$ still, new simple methods are in high demand.

Reductive amination of aldehydes and ketones is an important direct transformation of carbonyl compounds into amines. ${ }^{2}$ In this carbon-nitrogen bond forming process, aldehydes or ketones are allowed to react with ammonia, or primary- or secondary amines in the presence of a reducing agent to produce primary, secondary or tertiary amines, respectively. For increased efficiency, the formation of the imine and the reduction are carried out in a one-pot reaction. Under these conditions, the reduction of ketone or aldehyde must be slower than the imine formation and reduction to avoid alcohol by-products.

In order to carry out a direct reductive amination successfully, the choice of the reducing agent is critical. The most commonly used processes and reagents are: catalytic hydrogenation, ${ }^{3}$ 
borohydrides, ${ }^{4}$ and amine boranes ${ }^{5}$ to name but a few, but even water-soluble iron complexes have emerged very recently as catalysts. ${ }^{6}$

As a further possibility to broaden the scope of the methodology, these reaction conditions make it possible to carry out simultaneous reduction of other functional groups present in the starting carbonyl compounds. As a continuation of our interest in the synthesis of highly advanced indole intermediates substituted on the benzenoid part of the heterocycle ${ }^{7}$ we needed an easy access to 2-, 3-, and 4-dialkylaminomethylanilines. Diazotization of the aniline followed by Japp-Klingemann reaction with acetoacetic derivatives, and Fischer synthesis of the resulting hydrazone furnish 4-, 5-, 6-, and 7- dialkylaminomethyl-indole-2-carboxylates, respectively.

\section{Results and Discussion}

In this paper we describe our new synthetic approach toward the 2-, 3- and 4dialkylaminomethylated anilines $4 \mathbf{a}, \mathbf{b}, \mathbf{c}, \mathbf{d} ; \mathbf{5 b}$, c, d and $\mathbf{6 b}$, c, d, from 2-, 3-, and 4nitrobenzaldehydes by accomplishing the reductive amination of the formyl group and reduction of the nitro group in a single step, according to the following Scheme 1.

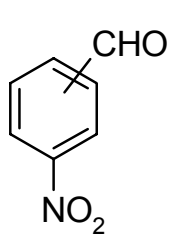

1

2

3

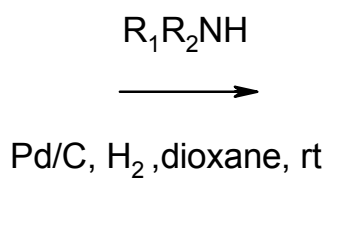

$\mathrm{R}_{1} \mathrm{R}_{2} \mathrm{NH}$

a morpholine

b piperidine

c pyrrolidine

d dimethylamine

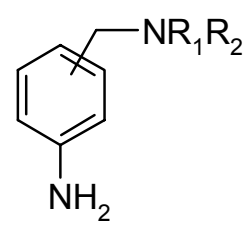

$4 \mathrm{a}, \mathrm{b}, \mathrm{c}, \mathrm{d}$

$5 \mathrm{~b}, \mathrm{c}, \mathrm{d}$

$6 \mathrm{~b}, \mathrm{c}, \mathrm{d}$
1, $4=$ para
2, $\mathbf{5}=$ meta
3, $6=$ ortho

\section{Scheme 1}

Our synthesis of $\mathbf{4 a}, \mathbf{b}, \mathbf{c}$, and $\mathbf{d} ; \mathbf{5 b}, \mathbf{c}, \mathbf{d}$, and $\mathbf{6 b}, \mathbf{c}, \mathbf{d}$ provides an alternative route to these dialkylamino-anilines that typically involves alkylation of secondary amines with 2-, 3-, and 4- 
nitrobenzyl chlorides followed by reduction of the nitro group to amine. ${ }^{8}$ In our hands, however, the first step, i.e., the alkylation with nitrobenzyl bromides, always failed, yielding mainly quaternary ammonium salts. When looking for an expedient procedure to obtain compounds $\mathbf{4 , 5}$ and 6, the 2-, 3- and 4-nitrobenzaldehydes seemed to be convenient and inexpensive starting materials, free from any health hazard (nitrobenzyl bromides are serious skin irritants). To carry out the aminomethylation and the reduction step as a one-pot reaction seemed feasible, as the reduction of the nitro- group must be preceded by aminomethylation, thus avoiding selfcondensation between the aniline and the formyl group. This comes from considerations that the addition of an aliphatic amine should be faster than that of an aniline: moreover, the addition of an amine onto an activated formyl function should be faster than the reduction of the nitro group. To ensure that such conditions persist during the entire reaction, the secondary amine should be applied in large excess. However, to put this one-pot process into practice we needed considerable experimentation. We started our investigations with 4-nitrobenzaldehyde. Most of the solvents, i.e., alcohols, ethers, acetic acid, aromatic- or chlorinated solvents, gave complex mixtures which were not considered attractive for further investigation. Altering the secondary amines or the reaction conditions gave no improvements. Finally, dioxane proved to be the solvent of choice to accomplish this reduction, providing $\mathbf{4 a}, \mathbf{4 b}$, and $\mathbf{4 c}$ in almost quantitative yields. In the case of dimethylamine, however, the yield of $\mathbf{4 d}$ was slightly decreased (65\%), possibly because the volatile amine decreased the partial pressure of hydrogen. The non-volatile amines also hindered the process because of catalyst poisoning: exhausted catalysts should be replaced by fresh ones at least once, to complete the reaction. Dry dioxane should be used, otherwise the water produced stops the reaction. The process can be followed conveniently by either measuring the consumption of hydrogen or by TLC; the reaction had a pale yellow color at the end. The work-up of the reaction mixture is simple: the catalyst was filtered off, the dioxane solution was rotary- evaporated, and the oily residue was crystallized by treatment with hexane to give $\mathbf{4 a}, \mathbf{b}, \mathbf{c}, \mathbf{d}$ as almost pure solids. The nitro-aldehydes $\mathbf{2}$ and $\mathbf{3}$, however, provided dialkylaminomethyl anilines $\mathbf{5 b}, \mathbf{c}, \mathbf{d}$ and $\mathbf{6 b}, \mathbf{c}, \mathbf{d}$ in lower yield. These products could be isolated by flash chromatography in $20-32 \%$ yield with no difficulty, as most of the by-products have much higher polarity than $\mathbf{5 b}, \mathbf{c}, \mathbf{d}$ and $\mathbf{6 b}, \mathbf{c}, \mathbf{d}$, or they are polymeric materials. With the ortho- derivatives, several bye products were isolated, among them 2-aminobenzyl alcohol and 2-aminobenzaldehyde, in 5-10\% amount. In the case of 3-nitrobenzaldehyde the by products were highly insoluble polymeric materials. Their formation might be a result of the increased basicity of 3-substituted anilines as compared to the 2-, and 4-regioisomers, leading to selfcondensation of 3 -formylaniline or its derivatives. 


\section{Experimental Section}

General Procedures. ${ }^{1} \mathrm{H}$ - and ${ }^{13} \mathrm{C}$ NMR spectra were recorded on a Bruker DRX 300 spectrometer in $\mathrm{CDCl}_{3}$, all $\delta$ values are given in ppm, TMS was used as an internal standard. All chemicals were reagent grade and used without further purification. Merck precoated silica gel $60 \mathrm{~F}_{254}$ sheets were used for TLC with the mobile phase ethyl acetate: pyridine: acetic acid: water 5:2.7:0.8:1.5 and Merck Kieselgel 60 was used for flash chromatography.

\section{General procedure for the preparation of 4a-d}

To a solution of 4-nitrobenzaldehyde $(25 \mathrm{~g}, 165 \mathrm{mmol})$ in dry dioxane $(500 \mathrm{ml})$ was added the appropriate amine (300 mmole) and $\mathrm{Pd} / \mathrm{C}(10 \%, 2.5 \mathrm{~g})$. Dimethylamine in dioxane $(15 \mathrm{~g} / 100 \mathrm{ml}$ solution) was added. The reaction mixture was hydrogenated for $18 \mathrm{hrs}$ then the catalyst was filtered off and replaced by fresh one (1.7 g). Hydrogenation was continued until the theoretical amount of hydrogen was consumed. By this time the reaction mixture had attained a pale yellow color (approx. $10 \mathrm{hrs)}$ ). The catalyst was filtered off and the clear solution was evaporated to dryness to give a solid (but in the case of $\mathbf{4 d}$, a colorless oil). Almost pure material was obtained by triturating the solid with hexane. The oil (4d) was purified by passing it through a short column of silica, in hexane: ethyl acetate, $4: 1$.

4-(Morpholinomethyl)aniline (4a). This compound was obtained as pale yellow crystals (26.3 g, 83\%); mp 97-100 ${ }^{\circ} \mathrm{C}$ (ethyl acetate), (lit. $\left.{ }^{9} \mathrm{mp} 98-99^{\circ} \mathrm{C}\right) ; \mathrm{R}_{\mathrm{f}}=0.76 ;{ }^{1} \mathrm{H}$ NMR $\delta=2.41(\mathrm{~m}, 4 \mathrm{H})$, 3.38 (s, 2H), 3.65 (bs, 2H), $3.70(\mathrm{~m}, 4 \mathrm{H}), 6.64(\mathrm{~d}, J=7 \mathrm{~Hz}, 2 \mathrm{H}), 7.09$ (d, $J=7 \mathrm{~Hz}, 2 \mathrm{H}) .{ }^{13} \mathrm{C}$ NMR, $\delta=53.8,62.9,67.1,114.9,127.2,130.2,145.5$.

4-(Piperidinomethyl)aniline (4b). This compound was obtained as pale yellow crystals ( $24 \mathrm{~g}$, $78 \%$ ); $\mathrm{mp} 85-88{ }^{\circ} \mathrm{C}$ (hexane, lit. $\left.{ }^{9} \mathrm{mp} 87-88{ }^{\circ} \mathrm{C}\right) ; \mathrm{R}_{\mathrm{f}}=0.62 ;{ }^{1} \mathrm{H}$ NMR $\delta=1.40(\mathrm{~m}, 2 \mathrm{H}), 1.56(\mathrm{~m}$, $4 \mathrm{H}), 2.35(\mathrm{~m}, 4 \mathrm{H}), 3.36(\mathrm{~s}, 2 \mathrm{H}), 3.60(\mathrm{bs}, 2 \mathrm{H}) ; 6.63(\mathrm{~d}, J=7 \mathrm{~Hz}, 2 \mathrm{H}), 7.08(\mathrm{~d}, J=7 \mathrm{~Hz}, 2 \mathrm{H}) .{ }^{13} \mathrm{C}$ NMR, $\delta=24.7,25.9,54.3,63.1,114.6,128.5,130.2,150.0$.

4-(Pyrrolidinomethyl)aniline (4c). This compound was obtained as white crystals (20.9 g, 71\%); mp 48-51 ${ }^{\circ} \mathrm{C}$ (hexane, lit. ${ }^{10} \mathrm{mp} 51{ }^{\circ} \mathrm{C}$ ); $\mathrm{R}_{\mathrm{f}}=0.64 ;{ }^{1} \mathrm{H}$ NMR $\delta=1.76(\mathrm{~m}, 4 \mathrm{H}), 2.47(\mathrm{~m}$, $4 \mathrm{H}), 3.50(\mathrm{~s}, 2 \mathrm{H}), 3.60(\mathrm{bs}, 2 \mathrm{H}), 6.62(\mathrm{~d}, J=7 \mathrm{~Hz}, 2 \mathrm{H}), 7.10(\mathrm{~d}, J=7 \mathrm{~Hz}, 2 \mathrm{H}) \cdot{ }^{13} \mathrm{C}$ NMR, $\delta=$ 23.4, 54.1, 60.0, 114.5, 129.0, 129.6, 145.1 .

4-(Dimethylaminomethyl)aniline (4d). This compound was obtained as a colorless oil (16.0 g, $65 \%) ; \mathrm{R}_{\mathrm{f}}=0.48 ;{ }^{1} \mathrm{H}$ NMR $\delta=2.13(\mathrm{~s}, 6 \mathrm{H}), 3.32(\mathrm{~s}, 2 \mathrm{H}), 3.65(\mathrm{bs}, 2 \mathrm{H}), 6.65(\mathrm{~d}, J=7 \mathrm{~Hz}, 2 \mathrm{H})$, $7.10(\mathrm{~d}, J=7 \mathrm{~Hz}, 2 \mathrm{H}) .{ }^{13} \mathrm{C}$ NMR $\delta=44.6,63.5,114.6,128.2,129.8,145.0$.

\section{General Procedure for the preparation of 5a-d}

The hydrogenation of 2- and 3-nitrobenzaldehydes was carried out in the presence of amines, as described for 4-nitro-benzaldehyde. The catalyst was filtered off and the clear solution was evaporated to dryness to give a yellow oil which was chromatographed on silica with hexane as eluent. In the case of $\mathbf{5 d}$ and $\mathbf{6 d}$, hexane: ethyl acetate $4: 1$ or 8:1 were used, respectively. 
3-(Piperidinomethyl)aniline (5b). Obtained as white crystals $(10.0 \mathrm{~g}, 32 \%)$; mp 107-110 ${ }^{\circ} \mathrm{C}$ (hexane, lit. $\left.{ }^{11} \mathrm{mp} 111{ }^{\circ} \mathrm{C}\right) ; \mathrm{R}_{\mathrm{f}}=0.60 ;{ }^{1} \mathrm{H} \mathrm{NMR} \delta=1.42(\mathrm{~m}, 2 \mathrm{H}), 1.57(\mathrm{~m}, 4 \mathrm{H}), 2.36(\mathrm{~m}, 4 \mathrm{H})$, $3.37(\mathrm{~s}, 2 \mathrm{H}), 3.62(\mathrm{bs}, 2 \mathrm{H}), 6.56(\mathrm{~d}, J=7 \mathrm{~Hz}, 1 \mathrm{H}), 6.68(\mathrm{~m}, 2 \mathrm{H}), 7.07(\mathrm{t}, J=8 \mathrm{~Hz}, 1 \mathrm{H}) .{ }^{13} \mathrm{C}$ NMR $\delta=24.5,26.1,54.7,64.1,113.9,116.1,119.8,129.1,139.9,146.5$.

3-(Pyrrolidinomethyl)aniline (5c). This compound was obtained as white crystals (8.2 g, 28\%); mp 69-71 ${ }^{\circ} \mathrm{C}$ (hexane); $\mathrm{R}_{\mathrm{f}}=0.65 ;{ }^{1} \mathrm{H}$ NMR $\delta=1.77(\mathrm{~m}, 4 \mathrm{H}), 2.50(\mathrm{~m}, 4 \mathrm{H}), 3.52(\mathrm{~s}, 2 \mathrm{H}), 3.60$ (bs, $2 \mathrm{H}), 6.56(\mathrm{~d}, J=7 \mathrm{~Hz}, 1 \mathrm{H}), 6.70(\mathrm{~m}, 2 \mathrm{H}), 7.08(\mathrm{t}, J=8 \mathrm{~Hz}, 1 \mathrm{H}) .{ }^{13} \mathrm{C} \mathrm{NMR} \delta=23.7,54.2$, 61.0, 113.9, 115.6, 119.4, 129.3, 141.0, 146.6. Anal. Calcd for $\mathrm{C}_{11} \mathrm{H}_{16} \mathrm{~N}_{2}$ : C, 74.96; H, 9.15; N 15.89. Found: C, 74.71; H, 8.96; N 16.00\%.

3-(Dimethylaminomethyl)aniline (5d). This compound was obtained as white crystals, $5.2 \mathrm{~g}$ (21\%); mp 44-46 ${ }^{\circ} \mathrm{C}$ (hexane, Lit. ${ }^{8} \mathrm{mp} 46{ }^{\circ} \mathrm{C}$ ); $\mathrm{R}_{\mathrm{f}}=0.50 ;{ }^{1} \mathrm{H}$ NMR $\delta=2.30(\mathrm{~s}, 6 \mathrm{H}), 3.70(\mathrm{~s}, 2 \mathrm{H})$, $6.65(\mathrm{~m}, 2 \mathrm{H}), 6.75(\mathrm{~s}, 1 \mathrm{H}), 7.10(\mathrm{~m}, 1 \mathrm{H}) .{ }^{13} \mathrm{C} \mathrm{NMR} \delta=45.0,64.0,114.0,115.5,119.2,128.9$, $138.8,146.4$.

2-(Piperidinomethyl)aniline (6b). This compound was obtained as yellow crystals, $7.5 \mathrm{~g} \mathrm{(24 \% );}$ $\mathrm{mp} 78-79{ }^{\circ} \mathrm{C}$ (hexane, Lit. $\left.{ }^{12} \mathrm{mp} 82.5{ }^{\circ} \mathrm{C}\right) ; \mathrm{R}_{\mathrm{f}}=0.63 ;{ }^{1} \mathrm{H}$ NMR $\delta=1.50(\mathrm{~m}, \mathrm{H}), 2.41(\mathrm{~m}, 4 \mathrm{H}), 3.8(\mathrm{~s}$, 2H), 4.5 (bs, 2H), $6.66(\mathrm{t}, J=7.6 \mathrm{~Hz}, 2 \mathrm{H}), 7.00(\mathrm{~d}, J=7.6 \mathrm{~Hz}, 1 \mathrm{H}), 7.08(\mathrm{t}, J=7.6 \mathrm{~Hz}, 1 \mathrm{H}).) .{ }^{13} \mathrm{C}$ NMR $\delta=24.4,26.0,54.0,62.7,115.2,117.2,122.7,127.9,130.2,147.0$.

2-(Pyrrolidinomethyl)aniline (6c). Obtained as yellow crystals $(6.1 \mathrm{~g}, 21 \%)$; mp 30-32 ${ }^{\circ} \mathrm{C}$ (hexane, lit. ${ }^{13} \mathrm{mp} \mathrm{31-32}{ }^{\circ} \mathrm{C}$ ); $\mathrm{R}_{\mathrm{f}}=0.62 ;{ }^{1} \mathrm{H}$ NMR $\delta=1.75(\mathrm{~m}, 4 \mathrm{H}), 2.45(\mathrm{~m}, 4 \mathrm{H}), 3.60(\mathrm{~s}, 2 \mathrm{H})$, $4.76(\mathrm{bs}, 2 \mathrm{H}), 6.63(\mathrm{~m}, 2 \mathrm{H}), 7.00(\mathrm{~d}, J=7 \mathrm{~Hz}, 1 \mathrm{H}), 7.07(\mathrm{t}, J=8 \mathrm{~Hz}, 1 \mathrm{H}) .{ }^{13} \mathrm{C}$ NMR $\delta=23.7$, $53.8,59.5,115.4,117.5,124.2,128.3,129.7,146.9$.

2-(Dimethylaminomethyl)aniline (6d). Obtained as yellow crystals (5.0 g, 20\%); mp 37-38 ${ }^{\circ} \mathrm{C}$ (hexane, lit. $^{8} \mathrm{mp} 36-37{ }^{\circ} \mathrm{C}$ ); $\mathrm{R}_{\mathrm{f}}=0.45 ;{ }^{1} \mathrm{H}$ NMR $\delta=2.28(\mathrm{~s}, 6 \mathrm{H}), 3.48(\mathrm{~s}, 2 \mathrm{H}), 4.72(\mathrm{bs}, 2 \mathrm{H}), 6.68$ $(\mathrm{d}, J=8 \mathrm{~Hz}, 1 \mathrm{H}), 6.74\left(\mathrm{dt}, J_{1}=8 \mathrm{~Hz}, J_{2}=1 \mathrm{~Hz}, 1 \mathrm{H}\right), 7.05(\mathrm{~d}, J=7 \mathrm{~Hz}, 1 \mathrm{H}), 7.16\left(\mathrm{dt}, J_{1}=7 \mathrm{~Hz}\right.$, $\left.J_{2}=1 \mathrm{~Hz}\right) .{ }^{13} \mathrm{C}$ NMR $\delta=44.8,63.2,115.2,117.3,123.0,128.3,130.3,146.7$.

\section{Acknowledgements}

The authors would like to thank the National Fund for Science and Research (OTKA Project. No. T75705) for financial support.

\section{References}

1. Van der Plas, H. C. Acc. Chem. Res. 1978, 11, 462.

2. (a) The Chemistry of Enamines, In Patai series: The Chemistry of Functional Groups; Rapoport, Z., Ed.; Wiley: New York, 1994. (b) Hutchins, R. O.; Hutchins, M. K. In Comprehensive Organic Synthesis; Trost, B. N., Ed.; Pergamon: Oxford: 1991; Vol. 8, p. 25 . 
3. Xing, L.; Cheng, C.; Zhu, R.; Zhang, B.; Wang, X.; Hu, Y. Tetrahedron 2008, 64, 11783.

4. (a) Hutchins, R. O.; Natale, N. R. Org. Prep. Proced. Int. 1979, 11, 201. (b) Abdel-Magid, A. F.; Carson, K. G.; Harris, B. D.; Maryanoff, C. A.; Shah, R. D. J. Org. Chem. 1996, 61, 3849 .

5. Burkhardt, E. R.; Coleridge, B. M. Tetrahedron Lett. 2008, 49, 5152.

6. Bhor, M. D.; Bhanushali, M. J.; Nandurkar, N. S.; Bhanage, B. M. Tetrahedron Lett. 2008, 49, 965.

7. Pete, B. Tetrahedron Lett. 2008, 49, 2835.

8. Stedman, E. J. Chem. Soc. 1927, 1902.

9. Shiraishi, M.; Aramaki, Y.; Seto, M.; Imoto, H.; Nishikawa, Y.; Kanzaki, N.; Okamoto, M.; Sawada, H.; Nishimura, O.; Baba, M.; Fujino, M. J. Med. Chem. 2000, 43, 2049.

10. Reppe, W. Justus Liebigs Ann. Chem. 1955, 596, 152.

11. Severin, T.; Schmitz, R.; Adam, M. Chem. Ber. 1963, 96, 3076.

12. Spaeth, E.; Kuffner, F.; Platzer, N. Chem. Ber. 1935, 68, 935.

13. Lellmann, W.; Pekrun, A. Justus Liebigs Ann. Chem. 1890, 259, 49. 